\title{
Population Ageing, Fiscal Pressure and Tax Smoothing: A CGE Application to Australia
}

\author{
Ross Guest \\ Griffith University \\ Australia
}

\begin{abstract}
This paper analyses the fiscal pressure from population ageing using an intertemporal CGE model, applied to Australia, and compares the results with those of a recent governmentcommissioned study. The latter study uses an alternative modelling approach based on extrapolation rather than optimizing behaviour of consumers and firms. The deadweight losses from the fiscal pressure caused by population ageing are equivalent to an annual loss of consumption of \$260 per person per year in 2003 dollars in the balanced budget scenario. A feasible degree of tax smoothing would reduce this welfare loss by an equivalent of $\$ 70$ per person per year. Unlike the extrapolation-based model, the CGE approach takes account of feedback effects of ageing-induced tax increases on consumption and labour supply, which in turn impact on the ultimate magnitude of fiscal pressure and therefore tax increases. However, a counter-factual simulation suggests that the difference in terms of deadweight losses between the two modelling approaches is modest at about $\$ 30$ per person per year.
\end{abstract}

JEL codes: H31, H32, J18, E21

\section{Corresponding author:}

Ross Guest

Professor of Economics

Griffith Business School

Griffith University

PMB 50

Gold Coast Mail Centre

Queensland 9726

Australia 


\section{Introduction}

Population ageing is currently occurring in most OECD countries, albeit at different rates, and is receiving considerable public policy attention. This is because the transition to older populations has potentially significant macroeconomic implications. Of particular concern to policy makers is the rising fiscal cost of health care, aged care and public pensions. There are also broader macroeconomic concerns, notably the negative effect on the growth of living standards from falling employment to population ratios. Related issues include the effect that population ageing may have on labour productivity, and on relative prices such as real exchange rates and the price of labour relative to capital.

The focus of this paper is on the fiscal effects of population ageing. Projecting the fiscal pressure caused by population ageing has become popular in OECD countries. For examples, see Auerbach, Gale and Orszag (2004) for the U.S., HM Treasury (2003) for the U.K., European Commission (2003) and Oksanen (2003) for Europe, and Farque and Muhleisen (2001) for Japan. Two examples for Australia are the Intergenerational Report (Australian Government, 2002) and the Productivity Commission (2005). The latter of these two Australian studies adopts the term "fiscal pressure" and defines it as "the extent to which increases in government spending outpace revenue growth” (p. 304) which, more precisely in the context of population ageing, means the decrease in the government's budget balance that is attributed to population ageing, directly or indirectly. Another measure of fiscal pressure is the fiscal gap, which is the immediate and permanent increase in taxes and/or decrease in government expenditures that would establish the same government debt to GDP ratio in the long run as holds currently (Auerbach, 1994). In this paper we will adopt the former measure of fiscal pressure. 
Broadly speaking, there are two approaches to modelling the fiscal impact of population ageing. One is a behavioural approach using an intertemporal computable general equilibrium (CGE) model and the other is an extrapolation approach which does not allow for behavioural feedback effects. Of course there can be combinations of the two. The CGE approach explicitly models feedback responses by forward-looking consumers and firms to changes in relative prices and quantities caused by population ageing. Such responses include the effects of tax rates on labour force participation and on substitution by consumers, both intertemporally and intratemporally, and the effects of employment growth on investment demand by firms. The outcomes from this approach are optimal in the sense of maximizing intertemporal social welfare. The extrapolation approach does not attempt to model optimizing behaviour of consumers or firms. Rather it projects behaviour based on trends and plausible scenarios about the future. ${ }^{1}$

Examples of the latter approach are the two Australian studies, both commissioned by the Australian Government, cited above. The aim of this study will be to compare the results obtained from a non-behavioural model with those from a CGE model. It will address questions such as: is fiscal pressure higher or lower using the CGE model, and by how much? What is the effect of fiscal pressure on social welfare? What are the welfare gains from feasible tax smoothing? The method adopted here is to take the government expenditure and demographic projections used in the non-behavioural model in Productivity Commission (2005), hereafter PC (2005), along with most of its key parameters, and to embed these in the CGE model.

\section{Projections of government expenditure.}

\footnotetext{
${ }^{1}$ This is not to say that the extrapolation approach is inferior. The fact that it lacks behavioural foundations may be seen by some as a strength, rather than a weakness, on the basis that an extrapolation of past trends is at least as
} 
In PC (2005) demographically-sensitive government spending is accounted for almost entirely by expenditure in health, aged care and education. ${ }^{2}$ We will restrict our attention to these areas in the empirical application. In each of these areas, the projections in PC (2005) are determined by three factors: data on current expenditure per person by age, projections of population by age, and a growth component consisting of the assumed rate of labour productivity growth plus a premium determined by assumptions about both the growth in unit costs and shifts in demand for the expenditure relative to demands for other goods and services. Letting $G_{D}$ be total demographically-sensitive government expenditure, $G_{D, j}=\sum_{i} \sum_{a=0}^{85} s_{i, a} N_{a, j} \cdot\left[(1+\gamma)\left(1+\omega_{i}\right)\right]^{j-1}$

where $i=$ health, aged case and education, $s_{i, a}$ is the expenditure of a person of age $a$ on category $i$ in $2003^{3}, \mathrm{~N}_{\mathrm{a}, \mathrm{j}}$ is the population of age $a$ in year $j, \gamma$ is the assumed constant annual rate of growth of labour productivity which is $1.75 \%$ (in the baseline simulation), and $\omega_{i}$ is the premium in the annual growth rate for expenditure in category $i$ which is $0.6 \%$ for health, $1.0 \%$ for aged care and zero for education. ${ }^{4}$

The demographic assumptions that generate the series $\mathrm{N}_{\mathrm{a}, \mathrm{j}}$ are described in PC (2005, p.7) and can be summarized as follows. The total fertility rate is expected to increase from the current level of 1.75 to 1.8 by 2013. Net overseas migration to Australia is held constant at approximately the current level of 115,000 persons per year which is $0.58 \%$ of current

\footnotetext{
reliable as a guide to the future as one based on assumptions about behaviour that may be inaccurate.

${ }^{2}$ In PC (2005) the increase in government spending on pensions is projected to be only 1.7 percent of GDP from 2004 to 2045, compared with an increase of 6 percent through health and aged care. The relatively small impact of ageing on public pension spending in Australia is due to its compulsory private pension system combined with means testing of the public pension.

${ }^{3}$ We are grateful to officers at the Productivity Commission for providing various spreadsheets with these calculations, as some spreadsheets were not included in the CD accompanying the Productivity Commission Report. ${ }^{4}$ For the assumptions about non-demographic growth rates in PC (2005) see p. 182 for aged care, p. 167 for health and p.208 for education.
} 
population. Life expectancy is projected to increase by 7.2 years for men and 5.3 years for women from 1999-2000 to 2051-51.

The outcome is that demographically-induced government expenditures on health, aged care and education are projected to generate fiscal pressure equal to 6 percent of GDP over the period from 2003-4 to 2044-5. That is, demographic change is projected to increase total government expenditure by 6 percent of GDP over this period. The pattern of this increase is illustrated by the series labelled "non-behavioural" in Figure 2, indicating that the extrapolation approach adopted in PC (2005) does not attempt to model any behavioural feedback effects.

The main point of departure of the CGE model is that in (1) all of the factors determining $\mathrm{G}_{\mathrm{D}}$ are exogenously given, whereas in the CGE model the growth rate of GDP, $\gamma$, is endogenous; and there is an additional factor affecting government consumption expenditure that is omitted from (1). The latter is the assumption that individuals choose to vary their consumption of government services in fixed proportion to their aggregate consumption in any given year. For example, if in a given year consumers choose to save more of their income by consuming less, they consume less of both government and private goods and services in equal proportion. A more sophisticated approach would be to model government consumption as a varying proportion of total consumption in any given year, but that is not done here. The main aim of the CGE simulations is to assess the impact of feedback effects on government consumption through effects on GDP and aggregate consumption.

The following equation is helpful in explaining how the feedback effects work.

$$
\left(\frac{G}{Y}\right)_{j}^{C G E}=\left(\frac{G}{Y}\right)_{j}^{P C} \frac{(C / Y)_{j}^{C G E}}{(C / Y)_{j}^{P C}}=\left(\frac{G}{C}\right)_{j}^{P C}\left(\frac{C}{Y}\right)_{j}^{C G E}
$$

where $G$ is aggregate government expenditure consisting of $\mathrm{G}_{\mathrm{D}}$ plus non-demographicallysensitive government expenditure, $\mathrm{G}_{\mathrm{N}} ; C$ is national consumption expenditure consisting of 
government and private consumption expenditure, and $Y$ is GDP. $\mathrm{G}_{\mathrm{N}}$ is held constant as a ratio to GDP and therefore variations in G/Y occur only through changes in $G_{D} / Y$. Government transfers are treated as negative taxes. The superscripts $C G E$ and $P C$ denote values applicable to the CGE model and the non-behavioural model in PC (2005).

Because the non-behavioural model treats both $G_{t}$ and $Y_{t}$ as exogenous and does not model private consumption, $(C / Y)_{j}^{P C}$ is implicitly exogenous and constant. This rules out any of the channels through which population ageing can endogenously affect $\mathrm{C}$ or $\mathrm{Y}$ in the nonbehavioural model. One such channel is consumer substitution effects - both intratemporal (between consumption and leisure) and intertemporal. Both of these substitution effects are determined by the changes in relative prices that are in turn caused by the effect of the fiscal costs of ageing on tax rates. The intratemporal substitution effect on leisure also affects GDP through its effect on labour supply. Finally, ageing impacts on $(C / Y)_{j}$ through the capital widening effect of labour force growth on investment demand. ${ }^{5}$

The CGE model adjusts $(G / Y)_{j}^{P C}$ according to (2) - that is, by multiplying $(G / Y)_{j}^{P C}$ by the ratio of $(C / Y)_{j}^{C G E}$ to $(C / Y)_{j}^{P C}$ where the latter is constant at its initial value in 2003. In the CGE model, the consumer determines $C_{j}$ by solving an intertemporal and intratemporal optimizing problem (see Section 3 and the Appendix), which implies from (1) that $(G / Y)_{j}^{C G E}$ is endogenous. The assumption that private and government consumption change in proportion in any given year, where the proportion is exogenously given, is implied by the exogenous ratio $(G / C)_{j}^{P C}$ in (2). This is equivalent to assuming that government and private consumption are perfectly complementary in generating utility. An equivalently arbitrary but opposite assumption which is

\footnotetext{
${ }^{5}$ Lower labour force growth implies less demand for capital for a given capital-labour ratio, therefore allowing a higher consumption share of output.
} 
sometimes adopted is that private and government consumption are perfectly substitutable (for example, Foertsch, 2004). Such arbitrary assumptions reflect the lack of evidence about the substitutability between private and government consumption in generating utility.

\section{Features of the CGE model}

This section describes the important features of the CGE model, including some non-standard features. The Appendix provides more detail.

The model is adapted from the two good open economy model in Obstfeld and Rogoff (1996, Ch. 4) where the two goods are a consumption good and leisure. The standard features of that model which are retained here can be summarized as follows. Both firms and consumers have perfect foresight. Firms determine the capital-labour ratio by equating the marginal product of capital with the cost of capital which depends on the interest rate and the rate of depreciation. The capital-labour ratio then determines the marginal product of labour which is equated to the real wage in order to determine the level of employment. Hence the demand for both labour and capital are determined.

Consumers derive utility from a composite index of consumption goods and leisure.

Consumers solve an intratemporal problem which determines the optimal allocation between the consumption good and leisure. This allocation depends on the relative price of consumption and leisure which in turn a function of the after-tax real wage. Consumers also solve an intertemporal problem in allocating the consumption index optimally over time. This allocation depends on the intertemporal price of the consumption index which in turn depends on the after-tax interest rate.

The model applied here has several modifications to the Obstfeld and Rogoff model. These modifications are designed to add realism and significantly reduce the initial jump and 
subsequent volatility that would otherwise occur in the optimal values of endogenous variables and therefore in the path of G/Y. Initial jumps tend to occur in macroeconomic models in which an initial steady state is subjected to a shock. In this case the shock is a demographic shock which is unanticipated but, once it arrives, agents have full knowledge of the demographic future. This a standard set up for modeling the macroeconomic outcomes of demographic change, the seminal example of which is Cutler et al. (1990). The Appendix reports a sensitivity simulation in which the modifications to the standard model are dropped and the resulting jump in $\mathrm{G} / \mathrm{Y}$ is clearly evident.

There are four such modifications, the equations for which are given in the Appendix. One is the introduction of imperfect capital mobility via a risk premium in the interest rate which is a function of the ratio of foreign liabilities to GDP. The risk premium acts as a self-correcting mechanism on foreign liabilities. As the ratio of foreign liabilities to GDP rises, the interest rate rises which boosts saving and reduces investment, thereby reducing foreign liabilities. Imperfect capital mobility adds realism to the model. There is extensive evidence that capital is not perfectly mobile internationally and is indeed quite immobile even for small open economies. For a discussion of the various explanations see Gordon and Bovenberg (1996); and for a survey of the evidence on the Feldstein-Horioka puzzle as an indicator of imperfect capital mobility see Coakley, Kulasi and Smith (1998).

There are two modifications to the model of consumption in Obstfeld and Rogoff (1996). One is the introduction of a reference level of consumption with which consumers compare their current level of consumption in deriving their utility. See Carroll et al. (1997) for a range of evidence in support of what they call "comparison utility". In the particular specification adopted here (see Appendix), the reference level of consumption is the previous period's consumption 
level. The effect of this is that consumers smooth out the growth in consumption, rather than the level of consumption, which acts to reduce the volatility in the optimal consumption path. The other modification with regard to consumption is the recognition that not all consumers are optimizers. Some consumers - in this case 30 percent - are rule-of-thumb consumers who consume a fixed proportion of their income every period, the proportion being the consumption share of income in the initial steady state. This assumption has become quite common in applied economy-wide models. In the context of population ageing, see for example, the OECD's MINILINK model in Turner et al., (1998). Again, the effect is to smooth out the aggregate consumption series.

The fourth modification to the standard model is the assumption of vintage capital rather than the more common assumption of homogeneous capital. With appropriate calibration, the assumption about capital does not affect the steady state outcomes for output, investment and the capital stock, although the path to the new steady state following an ageing shock is slightly different (for a discussion see Guest and McDonald, 2003). The vintage capital model has some practical advantages, especially in an open economy framework. One is that it obviates the need to introduce adjustment costs in the installation of capital. Adjustment costs are often introduced in open economy models, in cases where the interest rate is constant and there are constant returns to scale, in order to allow the optimal capital stock to be determined. An alternative to adjustment costs for this purpose is a vintage capital model because only the marginal vintage of capital, which is the current period's investment, needs to be determined, rather than the whole capital stock. In the case where the interest rate is not constant, the vintage capital model generates an investment series which does not exhibit the excessive volatility that can occur in 
homogeneous capital models. This is because in the vintage model changes in the interest rate lead to changes only in the marginal vintage of capital rather than the whole capital stock.

\section{Fiscal pressure}

As stated in the introduction, this study adopts the definition of fiscal pressure in PC (2005), that is, the increase in government spending to GDP that is caused by demographic change. The government faces the following dynamic budget constraint:

$\left(\frac{D^{g o v}}{Y}\right)_{j}=\left(\frac{D^{g o v}}{Y}\right)_{j-1}\left(\frac{1+r}{1+x}\right)_{j}+\left(\frac{G}{Y}\right)_{j}-\left(\frac{T}{Y}\right)_{j}$

where $D^{g o v}$ is government debt (net), $Y$ is GDP, $r$ is the real interest rate facing both the public and private sectors, $x$ is the growth rate of GDP, and $T$ is taxes (net of transfers) which are levied at a flat rate on both labour and capital income. ${ }^{6}$

In a steady state, foreign liabilities are a constant proportion of GDP which implies a steady state (SS) value for C/Y given by:

$$
\left(\frac{C}{Y}\right)_{S S}=1-\left(\frac{I}{Y}\right)_{S S}-\left(\frac{r-x}{1+x}\right)_{S S}\left(\frac{D}{Y}\right)_{S S}
$$

where $I$ is national investment and $D$ is foreign liabilities. Substituting for $C / Y$ from (4) into (2) gives the steady state level of government expenditure to GDP:

$$
\frac{G}{Y}_{S S}=\left(\frac{G}{C}\right)_{S S}\left(1-\frac{I}{Y}-\left(\frac{r-x}{1+x}\right) \frac{D}{Y}\right)_{S S}
$$

Furthermore, the steady state value of $(I / Y)$ is given by

\footnotetext{
${ }^{6}$ We constrain the tax rate on capital to be equal to the tax rate on labour income. This is important later when we discuss tax smoothing where the government chooses an optimal tax rate. In that case the choice refers to the choice of the labour income tax rate; the capital income tax rate is constrained to be equal to that rate. This is done for simplicity in order to abstract from the problem of choosing the optimal tax rate on capital. Floden (2003) employs a somewhat similar assumption. For a discussion of the optimal tax rate on capital see Chamley (1986).
} 


$$
\frac{I}{Y}_{S S}=\left(\frac{x+\delta}{1+x}\right)\left(\frac{K}{Y}\right)_{S S}
$$

where $\delta$ is the depreciation rate. Substituting (6) into (5) gives

$$
\frac{G}{Y S S}_{S S}\left(\frac{G}{C}\right)_{S S}\left(1-\left(\frac{x+\delta}{1+x}\right)\left(\frac{K}{Y}\right)-\left(\frac{r-x}{1+x}\right) \frac{D}{Y}\right)_{S S}
$$

Subtracting $(G / Y)_{0}$ from equation (6) gives an expression for the long run $^{7}$ fiscal pressure due to ageing. Equation (7) consists of two terms: the exogenous level of $(G / C)_{S S}$ and an expression for $(C / Y)_{S S}$. Ageing has a positive effect on the latter term, given $(K / Y)>(D / Y)$ which implies positive SS national wealth, and that $\mathrm{X}_{\mathrm{SS}}$ is lower due to lower steady state employment growth. ${ }^{8}$ Therefore long run fiscal pressure is higher than it is in the non-behavioural model where $(C / Y)_{j}$ is exogenous. This is borne out by the empirical application as illustrated in Figure 1 and to which we now turn.

\section{Empirical results}

Figure 1 compares $(G / Y)_{j}$ from the CGE model with that generated by the non-behavioural model. The path of $(G / Y)_{j}$ illustrates ageing-induced fiscal pressure. The CGE model predicts higher fiscal pressure than that for the non-behavioural model after about 10 years, the difference stabilising at about 1 percent of GDP. The gap between the two series is explained by movements in $(C / Y)_{j}$ (see equation (1)). The series for $(C / Y)_{j}{ }^{C G E}$ is plotted in Figure 2. Recall that the series for $(C / Y)_{j}{ }^{P C}$ is constant because there are no behavioural feedback effects in that model. The new steady state level of $(C / Y)_{j}{ }^{C G E}$ is higher than the initial level because the new steady state employment growth is lower. This is explained by equations (4) and (6) which show

\footnotetext{
${ }^{7}$ Here the terms "long run” and "steady state” are used synonymously.

${ }^{8}$ This is simply the open economy analogue to the Solow effect which refers to the capital widening effects of employment growth on investment - in particular, slower employment growth lowers investment and therefore allows higher consumption as a share of output.
} 
that $(C / Y)_{j}$ is a function of $x_{j}$ which is the sum of employment growth and labour productivity growth. Lower employment growth implies less demand for new capital (the Solow effect implied in (6)), which is only partially offset by an analogous open economy effect with respect to new debt. ${ }^{9}$

The path of $(C / Y)_{j}$ to the new higher steady state level depends on both the path of $C$ and the path of $Y$. The path of $C$ is determined by substitution effects, both intratemporal and intertemporal, which can work in opposite directions. The net effect depends on the relative size of the two elasticities (see Appendix for derivation and Section 5.2 below for sensitivity analysis). These effects can be explained intuitively as follows. The two relative prices that create substitution effects are the after-tax wage and the interest rate. We deal first with the aftertax wage, defining this as the price of labour in efficiency units because we are interested in changes in consumption relative to output. The after-tax wage is falling in response to population ageing because the upward effect of fiscal pressure on the tax rate is greater than the upward effect of lower employment growth on the pre-tax wage. A lower after-tax wage induces workers to substitute leisure for consumption (see Figure 3). This intratemporal substitution effect causes consumption to fall as the tax rate rises. Against this, however, is the net of two intertemporal effects on consumption. We have just noted that the after-tax wage, the price of consumption relative to leisure, is falling when the tax rate is rising. A falling price of consumption causes consumers to postpone consumption, causing consumption to rise over time. This effect therefore works in the opposite direction to the intratemporal effect. There is, however, an additional intertemporal effect. Population ageing causes lower after-tax interest rates due to less demand for capital relative to the supply of capital through saving, which lowers

\footnotetext{
${ }^{9}$ The Solow effect in the open economy applies not just to capital, $K$, but to wealth defined as $(K-D)$. Lower employment growth means that there are fewer new workers available to saddle with new debt financed by
} 
pre-tax interest rates. Lower interest rates imply a lower return to saving, causing consumers to bring consumption forward, leading to a declining consumption path. The latter intertemporal effect turns out to be the stronger of the two. Hence both the intratemporal effect and the intertemporal effect reinforce each other in lowering consumption over time.

The path of $Y$ - again, net of productivity growth - depends on the path of the cost of capital. It also depends on employment growth which is partly exogenous and partly endogenous, the latter occurring through the effect on the leisure/work trade off discussed above.

Clearly, all of the above effects on $C$ and $Y$ are difficult to disentangle, which is why the simulations are useful. But is the effort worth it? That is, is the variation in $(C / Y)_{j}$ of sufficient importance to warrant the CGE analysis compared with the non-behavioural approach? A difference in fiscal pressure of 1 percent of GDP is perhaps not much. In order to evaluate this magnitude in welfare terms, a counter-factual simulation is run in which the exogenous series $(G / C)_{j}{ }^{P C}$ is adjusted downwards so that the series for fiscal pressure, $(G / Y)_{j}{ }^{C G E}$ matches the original series $(G / Y)_{j}^{P C}$. Continuous balanced budgets are assumed (tax smoothing is considered later). The difference between the consumption paths between the counter-factual case and the base case reflects the difference in the paths of tax rates and therefore the difference in deadweight losses. Social welfare in the base case simulation is 2.2 percent lower than in the counter-factual simulation, implying that the non-behavioural model has understated the welfare cost of fiscal pressure by 2.2 percent relative to the outcome from the CGE model. This difference in social welfare can be expressed in terms of annual consumption by comparing the optimal consumption paths under the two simulations. The result is a difference in annual consumption of 0.1 percent which amounts to $\$ 30$ dollars $^{10}$ per person per year (in 2003 dollars). 
Hence we can say that, compared with the CGE outcome, the non-behavioural model has underestimated the cost of fiscal pressure by $\$ 30$ per person per year.

The total deadweight losses from fiscal pressure can be similarly calculated, by running another counter-factual simulation in which population ageing occurs but does not cause any fiscal pressure. This is simulated by setting $(G / C)_{j}^{P C}=(G / C)_{l}^{P C}$ for all $\mathrm{j}$, which could only be achieved if all of the fiscal costs of ageing were fully offset by reductions in other government expenditure. In the first instance we assume balanced budgets in every year; and later compare this case with the tax smoothing scenario. In the balanced budget case the loss of social welfare due to fiscal pressure is 13 percent in total over 100 years. This translates into an average annual loss of consumption of 0.87 percent which is equivalent to a loss of approximately $\$ 260$ of total consumption (private plus social) per person per year (in 2003 dollars). ${ }^{11}$ This is the dollar cost of the deadweight losses that can be attributed to the fiscal pressure from population ageing.

The question to which we now turn is: what difference would tax smoothing make to these welfare costs? Table 1 summarises the welfare costs of fiscal pressure under the two cases which have been discussed and under the tax smoothing case to be considered next.

\subsection{Tax smoothing}

Floden (2003) conducted a comparison of the welfare costs of tax smoothing in the context of population ageing for the U.S. and a number of European countries. His study was motivated by the finding in Cutler et al (1990) that the deadweight losses were sufficiently small to conclude that "there is only a weak tax-efficiency case for prepaying the costs of the future dependency burden”. Floden finds that this is true for the U.S. but not for most European countries because 
they have higher tax rates and hence for those countries the gains from limiting further increases in tax rates are greater. He finds that the percentage gain from tax smoothing in terms of consumption per year per person is approximately zero (to two decimal places) for the U.S. but is up to 0.5 percent for some European countries. The CGE model in Floden (2003) has similarities with the model here; though an important difference is his assumption that fiscal costs of ageing per capita remain constant for all years. This difference is critical because the very purpose here is to analyse the effect of rising fiscal costs per capita due to ageing.

Two tax smoothing scenarios are simulated and the results illustrated in Figure 4. One is a "pure" smoothing scenario in which the tax rate is approximately constant over the projection period. ${ }^{12}$ As Figure 4 shows, this requires an initial jump in the tax rate of several percent of GDP. This scenario minimizes the deadweight losses from taxation. However, it is a hypothetical exercise because, first, it would be politically impossible to suddenly increase the tax burden by several percent of GDP; and, second, it would impose substantial adjustment costs on consumers and firms which are not modeled here. In the second scenario the path of the tax rate is chosen so that it increases gradually and faster than in the balanced budget case, but not as fast as the "pure" smoothing case. We describe this scenario as the "feasible" smoothing scenario that reduces but does not minimize the deadweight losses.

The effect of tax smoothing is to increase social welfare by 7.0 percent and 4.9 percent in the pure and feasible scenarios, respectively, and which implies an average gain in consumption in the two cases of, respectively, 0.7 percent and 0.23 percent, or about $\$ 200$ and $\$ 70$ (in 2003 dollars), per person per year. Whether this is worth doing depends on whether these gains

\footnotetext{
${ }^{11}$ The calculation is done by comparing the optimal consumption paths under the counter-factual and base case simulations, and using the following data. Total final consumption expenditure in 2002/3 was \$590,050 million and the total population was 19.8 million.
} 
outweigh the costs of tax smoothing in terms of the menu costs and other adjustment costs caused by bringing forward tax increases. Also, although judgements about intertemporal equity are captured by the social welfare function, there is the question of the effect of tax increases on intratemporal equity - that is, between different consumers at a point in time - that are assumed away here by the representative agent framework and the assumption of a flat rate of tax on all income. Answers to these questions would require a microsimulation analysis.

\subsection{Sensitivity analysis}

A sensitivity analysis was conducted with respect to the two consumption substitution elasticities, the discount rate, and the non-standard features of the CGE model discussed in Section 3. The role of the substitution elasticities was explained above in intuitive terms and is derived in the Appendix. The magnitude of the difference between these two elasticities is potentially important because it affects the path of consumption to the new steady state. Hence a simulation is run where the difference is large and one where the difference is small. The effect on fiscal pressure is reported in Table 2. The effect of the difference between the two elasticities is clearly miniscule. One reason is that any substitution of leisure for consumption affects both the numerator and denominator of $(C / Y)_{j}$ and therefore $(G / Y)_{j}$. More leisure implies less consumption but also less labour supply and therefore less output. Hence there is considerably more variation in the leisure/consumption ratio among the sensitivity simulations than there is in fiscal pressure. The same applies to the effect on living standards - that is, there is non-trivial variation in the response of living standards (consumption per capita) among the alternative simulations but this does not show up in the outcomes for fiscal pressure. These differences, in

\footnotetext{
${ }^{12}$ The optimal tax rate is not exactly constant because it must vary slightly in order to smooth the relative price of leisure which implies smoothing the after-tax real wage (Floden, 2003; Andersen and Dogonowski, 2004).
} 
terms of leisure/consumption and living standards, are interesting for other purposes but are of secondary importance for this paper.

Also, the sensitivity of the consumption path and hence fiscal pressure to the degree of intertemporal substitution is also small. The sensitivity of fiscal pressure to the difference between the two elasticities therefore turns out to be small, as illustrated in Table 2. This table also indicates that the sensitivity to the world interest rate is small. The reason is that it is not the interest rate itself that affects the consumption path to the new steady state but rather the difference between the interest rate and the rate of time preference. This difference is little affected by the choice of world interest rate because the rate of time preference adjusts, as follows (see also the Appendix):

$\theta=r_{S S}\left(1-t_{S S}\right)-\beta \gamma$

where $\theta$ is the rate of time preference, $\beta$ is the reciprocal of the intertemporal elasticity of substitution, and $\gamma$ is the steady state growth rate of labour productivity. Hence a change in the interest rate is offset by a change in the rate of time preference, which leaves the consumption path virtually unchanged. Indeed the consumption path and hence the path of fiscal pressure turns out to be remarkably robust. It can be affected somewhat by the parameter that determines the responsiveness of the interest rate to foreign liabilities. But it takes rather large changes in this parameter to have a material effect on the pattern of consumption.

Finally, a simulation was conducted in which several of the non-standard features of the CGE model are dropped. In this simulation, the risk premium in the interest rate is set equal to zero (yielding a constant interest rate which is the perfect capital mobility case or small open economy case), all consumers are intertemporal optimisers (that is, there are no rule-of-thumb 
consumers), and there is no reference consumption in the utility function. The results for fiscal pressure are given in the far right hand column of Table 2. As anticipated and discussed in Section 3, the series for fiscal pressure is more volatile, which is caused by a larger initial jump in consumption and subsequent higher volatility in the consumption path. Justification, with literature support, was provided in Section 3 for introducing each of the non-standard features of the CGE model which have the effect of smoothing out the consumption path and therefore the path of fiscal pressure.

\section{Conclusion}

This study has compared the fiscal pressure from population ageing in Australia using a CGE model with that using a non-behavioural model, based mainly on extrapolation of trends, which was used in a government-commissioned study (Productivity Commission, 2005). The CGE approach allows for feedback effects of tax increases on consumption and labour supply, which in turn affect the ultimate degree of fiscal pressure. With balanced budgets, the deadweight losses from ageing-induced fiscal pressure amount to \$260 per person per year in 2003 dollars, or 0.87 percent of total final consumption. The non-behavioural model yields a slightly lower estimate of deadweight losses. A feasible degree of tax smoothing could reduce these deadweight losses by about a quarter.

The strengths of the CGE approach are also arguably its weaknesses. That is, it requires assumptions about behavioural parameters - especially elasticities of substitution in consumption - and is susceptible to all of the well-known criticisms of representative agent macroeconomic modelling. Other controversies concern assumptions about initial and terminal steady states. The analysis of tax smoothing also has limitations. For example, large initial rises in tax rates impose 
adjustment costs on consumers and firms and would be difficult to achieve in practice due to political constraints. Despite its limitations, this paper addresses important questions with regard to the welfare effects of fiscal pressure and tax smoothing which have so far received little attention. 


\section{Appendix}

This Appendix describes the CGE model in more detail than the intuitive sketch given in Section 3 in the main text.

\section{Firms}

Firms produce output according to a putty-clay vintage production function with Cobb-Douglas technology. The reasons for a assuming vintage rather than homogeneous capital are discussed in Section 3 of the text. For a comparison of vintage versus homogeneous capital production functions in the context of population ageing see Guest and McDonald (2003). Output, Y, produced by $V$ vintages of capital, as follows:

$Y_{j}=\sum_{k=0}^{V-1}\left[(1-\delta)^{k} A_{j-k}\left(I_{j-k}\right)^{\alpha}\left[L_{j-k-1}\left(n_{j-k}+\delta\right)\right]^{1-\alpha}\right]$

where $A$ is an efficiency parameter, $I$ is investment, $L$ is labour, $n$ is the growth of labour, $\delta$ is the depreciation rate. Equation (A1) can be approximated by

$$
Y_{j}=Y_{j-1}(1-\delta)+A_{j} I_{j}^{\alpha}\left(L_{j-1}\left(n_{j}+\delta\right)\right)^{1-\alpha}
$$

Investment is determined by the first order condition that the after-tax net marginal product of capital (net of depreciation) less is equal to the after-tax cost of capital, $r_{j}(1-t)$, where the flat tax rate, $\mathrm{t}$, is levied on income from both labour and capital.

Hence $\left(\frac{d Y_{j}}{d I_{j}}-\delta\right)\left(1-t_{j}\right)=r_{j}\left(1-t_{j}\right)$

which, using (A2), gives the optimal level of investment:

$I_{j}=\left(\frac{A \alpha}{r_{j}+\delta}\right)^{1 / 1-\alpha} L_{j-1}\left(n_{j}+\delta\right)$

The real wage, $w_{j}$, is equal to marginal product of labour:

$$
w_{j}=A_{j}(1-\alpha)\left(\frac{I_{j}}{L_{j-1}}\right)^{\alpha}\left(n_{j}+\delta\right)^{1-\alpha}
$$

\section{Consumers}

The consumer's optimizing problem is set up analogously to the two good model in Obstfeld and Rogoff, 1996, Ch. 4). The algebra is facilitated by expressing variables in efficiency units per capita by $\left(A^{1 / 1-\gamma} N\right)_{j}$, where $\mathrm{N}$ is population. Lower case letters and symbols denote the variable in efficiency units per capita. Consumers derive utility from a composite index of consumption goods, C, and leisure, $S$ :

$\Pi_{j}=\left[\mu^{1 / \psi} C_{j}^{\psi-1 / \psi}+(1-\mu)^{1 / \psi} S_{j}^{\psi-1 / \psi}\right]^{\psi / \psi-1}$

Consumption goods consist of social, G, and private goods, the mix of which is given by the exogenous coefficients $(\mathrm{G} / \mathrm{C})_{\mathrm{j}}$ : 
$C_{j}=\overline{\left(\frac{G}{C}\right)_{j}} C_{j}+\overline{\left(1-\frac{G}{C}\right)_{j}} C_{j}$

A proportion, $\xi$, of consumers are rule-of-thumb consumers who consume a fixed proportion of their income in every period. Again, the discussion in Section 3 provides support for two non-standard features of the model of consumption - that is, a reference level of consumption and a proportion of consumers who do not optimise intertemporally but instead adopt rule-of-thumb consumption behaviour. The remaining consumers are intertemporal optimizers who maximise the following intertemporal utility function:

$U=\sum_{j=1}^{\infty}\left[\frac{\Pi}{Z}\right]_{j}^{1-\beta} \frac{(1+\theta)^{1-j}}{1-\beta} \quad \mathrm{j}=1, . ., \mathrm{h}$

where $Z_{j}$ is a reference stock of the consumption index and is set equal to $\Pi_{j-1}$.

The first order condition yields the Euler equation:

$\frac{\dot{\pi}}{\pi}=\frac{1}{\beta}\left(\frac{\partial r}{\partial d} d+r(1-t)-\dot{P}-\theta+(\beta-1) \frac{\dot{z}}{z}\right)-\gamma$

where $\gamma$ is labour productivity growth, and $P$ is the price of the composite consumption index, $\Pi$, in terms of the numeraire, $C$, and is given by

$P_{j}=\left[\mu+(1-\mu)\left(w_{j}\left(1-t_{j}\right)\right)^{1-\psi}\right]^{1 / 1-\psi}$

All consumers solve an intratemporal problem in allocating the consumption index between consumption and leisure, yielding the following optimal outcomes:

$c_{j}=\mu P_{j}^{\psi} \pi_{j}$

$s_{j}=(1-\mu)\left(\frac{P}{w(1-t)}\right)_{j}^{\psi} \pi_{j}$

Substituting (A11) into (A9) gives the Euler equation for consumption of goods

$\frac{\dot{c}}{c}=(\psi-\sigma)\left(\frac{\dot{P}}{P}\right)+\sigma\left(\frac{\partial r}{\partial d} d+r(1-t)-\theta+(\beta-1)\left(\frac{\dot{z}}{z}\right)\right)-\gamma$

where $\sigma=\frac{1}{\beta}$

Therefore

$\frac{\partial \dot{c} / c}{\partial \dot{P}^{C}}=\psi-\sigma$

Letting $w_{a}=w(1-t)$, and since $\frac{\partial P}{\partial w_{a}}>0$, then $\frac{\partial \dot{c} / c}{\partial w_{a}}>0$ iff $\psi-\sigma>0$

This result shows that the response of goods consumption to an increase in the tax rate depends on the relative strength of the intratemporal and intertemporal substitution parameters, $\psi$ and $\sigma$, respectively (see discussion in the text).

There is assumed to be a risk premium in the interest rate which is a function of the ratio of foreign liabilities to GDP (see discussion in Section 3 of text):

$r_{j}=\bar{r}+\lambda\left(\frac{d}{y}\right)_{j}$

Consumers and firms are collectively constrained by the standard national accounting identity which gives the equation of motion for foreign liabilities. 
$\dot{d}=(r(d)-x) d+c\left(\frac{N}{L}\right)+i-y$

where $x$ is the sum of the rates of growth of labour productivity and labour.

The steady state implies that $\dot{d}=0$ and $\dot{c}=0$ which yields the following steady state equations (in discrete time):

$c_{S S}=\left(\frac{L}{N}\right)_{S S}\left(y-i-\left(\frac{r(d)-x}{1+x}\right) d\right)_{S S}$

$\theta=r_{S S}\left(1-t_{S S}\right)-\beta \gamma$

\section{The labour market}

Labour supply, $\mathrm{L}_{\mathrm{j}}$ is given by $L_{j}=e_{j} \bar{L}_{j}$ where $\bar{L}_{j}$ is the exogenously given size of the labour force, and $e_{j}$ is work intensity defined as $e_{j}=\frac{1}{S_{j}}$ and $e_{1}=1$. Equilibrium in the labour market is determined as follows. The interest rate determines the marginal product of capital and therefore the marginal product of labour, which in turn determines the real wage. The real wage determines labour supply and, given the assumption of no unemployment, labour demand is set equal to labour supply.

\section{The government sector}

This was discussed in some detail in Sections 2 and 4 of the text.

\section{Calibrating the initial steady state}

Table A1 gives those parameter values that are set exogenously. They are adopted from several sources: PC (2005), similar CGE models in the literature, and/or values implied by calibrating the initial steady state to fit actual data for the Australian economy.

\begin{tabular}{|l|c|}
\hline \multicolumn{2}{|c|}{ Table A1. Parameter values and initial values of some variables (base case) } \\
\hline Steady state labour productivity growth rate, $\gamma$ & 0.0175 \\
\hline World interest rate, $\mathrm{r}$ & 0.04 \\
\hline Capital elasticity of output, $\alpha$ & 0.25 \\
\hline Steady state capital to output ratio & 3.0 \\
\hline Initial tax rate, $\mathrm{t}=\mathrm{T} / \mathrm{Y}$ & 0.3 \\
\hline Steady state foreign liabilities to GDP ratio, D/Y & 0.6 \\
\hline Elasticity of marginal utility w.r.t. consumption index, $\beta$ & 2.0 \\
\hline Elasticity of substitution between consumption and leisure, $\psi$ & 0.8 \\
\hline Slope of interest rate function $[\Delta r / \Delta(d / y)]$ & 0.02 \\
\hline Proportion of rule-of-thumb consumers, $\xi$ & 0.3 \\
\hline
\end{tabular}



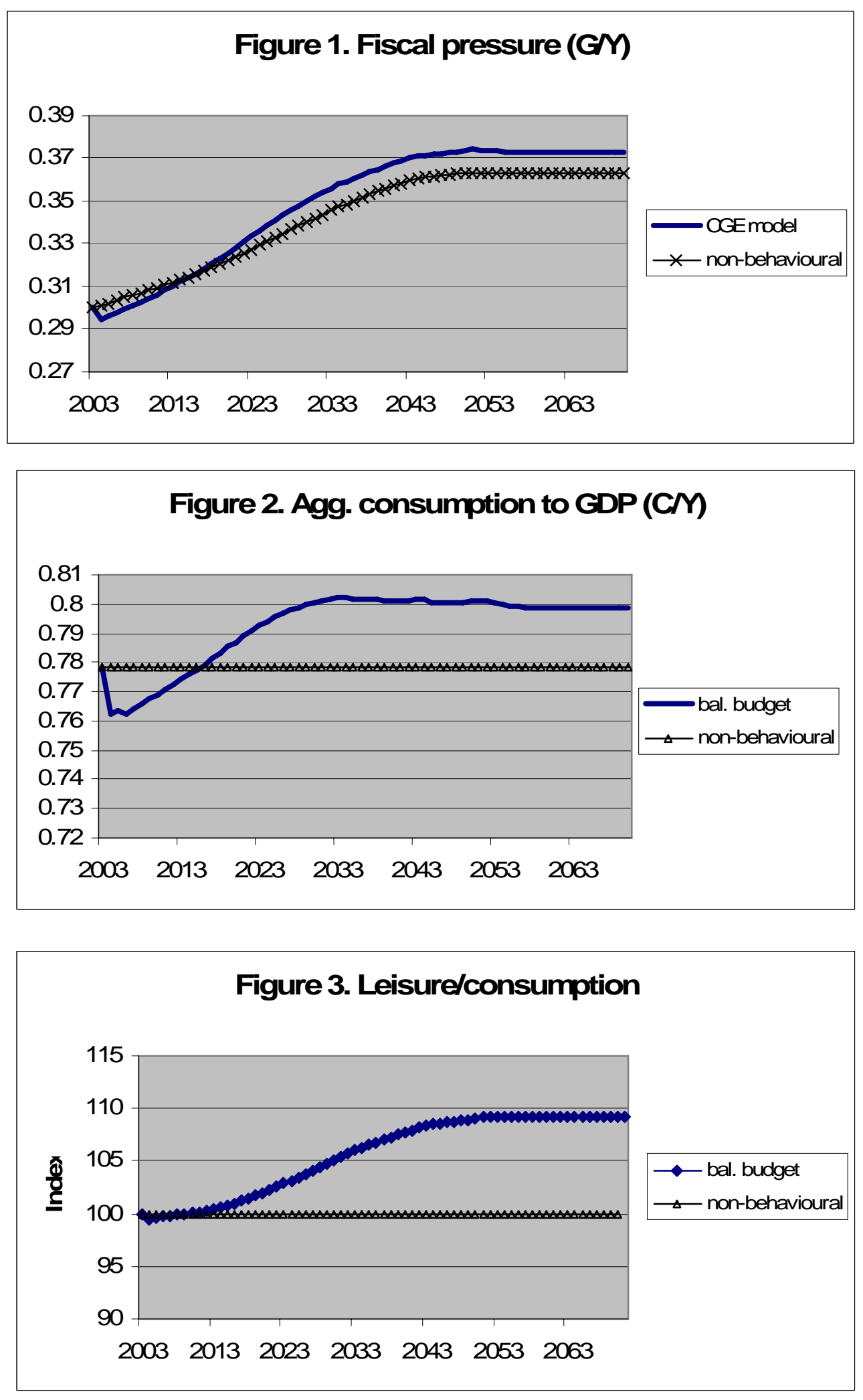


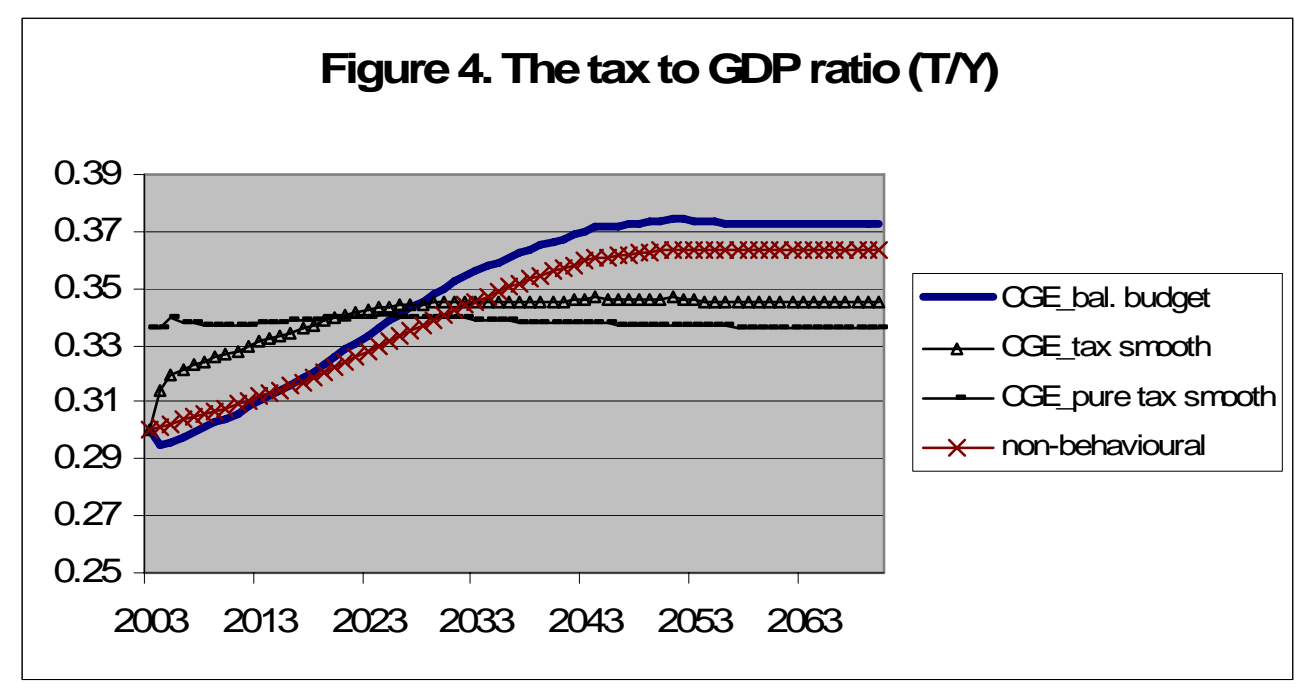

Table 1. Welfare cost of fiscal pressure Annual (\%) cost in consumption per person

$\begin{array}{ccc} & \text { \% } & \text { in 2003 \$ } \\ \text { Base case } & 0.87 & 259 \\ \text { Feasible tax smoothing } & 0.64 & 192 \\ \text { Pure tax smoothing } & 0.17 & 51 \\ \text { non-behavioural model } & 0.77 & 229\end{array}$

Table 2. Sensitivity Analysis

Fiscal pressure: increase in (G/Y) (\%)

\begin{tabular}{lrrrrc} 
& \multicolumn{1}{c}{ Base } & $\psi-\sigma=$ large & $\psi-\sigma=$ small & world $r=3 \%$ & Base-alternative* \\
2010 & 0.44 & 0.28 & 0.27 & 0.43 & -4.07 \\
2020 & 2.57 & 2.64 & 2.40 & 2.46 & 0.72 \\
2030 & 5.00 & 5.13 & 5.00 & 4.88 & 6.70 \\
2040 & 6.62 & 6.67 & 6.54 & 6.55 & 10.16 \\
2050 & 7.37 & 7.39 & 7.30 & 7.34 & 10.87 \\
2070 & 7.31 & 7.30 & 7.28 & 7.30 & 9.20
\end{tabular}

*Base-alternative refers to the base case with the following alternative assumptions: a constant interest rate (i.e. zero risk premium), no rule of thumb consumers, and no reference level of consumption in the utility function. 


\section{References}

Andersen, T. and Dogonowski, R. (2004) "What Should Optimal Income Taxes Smooth?” Journal of Public Economic Theory 6, 3, 491-507

Aurbach, A. (1994) "The US Fiscal Problem: Where We Are, How We Got There, and Where We’re Going” NBER Working Paper, No. 4709

Auerbach, A., Gale, W. and Orszag, P (2004) “The Fiscal Gap and Retirement Saving Revisited” Tax Notes, July 26, The Brookings Institute, Washington.

Australian Government (2002) Australian Government (2002) “Intergenerational Report 20022003”, 2002-2003 Budget Paper No. 5, Commonwealth of Australia, Canberra.

Barro, R. (1979) “On the Determination of Public Debt” Journal of Political Economy, 87, 5, 940-971

Barro, R. (1981) “Output Effects of Government Purchases” Journal of Political Economy, 89, 6, 1086-1121

Carroll, C. D., Overland, J. and Weil, D, N. (1997), “Comparison Utility in a Growth Model”, Journal of Economic Growth, 2, 339-367

Chamley, C. (1986) “Optimal Taxation of Capital Income in General Equilibrium with Infinite Lives” Econometrica, 54, 1, 607-622

Coakley, J., Kulasi, F. and Smith, R. (1999), “The Feldstein-Horioka Puzzle and Capital Mobility: A Review”, International Journal of Finance and Economics, 3, 169-188

Cutler, D.M., Poterba, J.M., Sheiner, L.M. and Summers, L.H. (1990) "An Aging Society: Opportunity or Challenge?" Brookings Papers on Economic Activity, (1), pp.1-74. European Commission (2003) “Public Finances in EMU 2003”, Commission of the European Communities, Brussels. 
Farque, H. and Muhleisen, M. (2001) “Population Ageing in Japan: Demographic Shock and Fiscal Sustainability” IMF Working Paper, 01/40, International Monetary Fund. Floden, M (2003) “Public Saving and Public Policy Coordination in Aging Economies”,

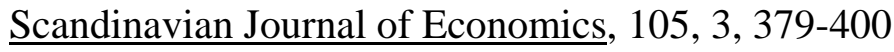

Foertsch, T. (2004) “Macroeconomic Impacts of Stylized Tax Cuts in an Intertemporal Computable General Equilibrium Model”, Technical Paper Series, Congressional Budget Office, Washington, DC.

Gordon, R.H. and Bovenberg, A.L. (1996), “Why is Capital So Immobile Internationally? Possible Explanations and Implications for Capital Income Taxation”, American Economic Review, 86, 5, 1057-1075.

Guest, R. and McDonald, I.M. (2003) "Vintage Versus Homogeneous Capital in Simulations of Population Ageing: Does it Matter?”, Applied Economics Letters 10, 3, 149-154

HM Treasury (2003) “Long-Term Public Finance Report: Fiscal Sustainability with and Ageing

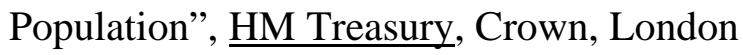

Obstfeld, M. and Rogoff, K. (1996), “Foundations of International Macroeconomics”, MIT Press.

Oksanen, H. (2003) “Population Ageing and Public Finance Targets” European Commission Economic Papers, No. 193, December, European Commission, Brussels. Productivity Commission (2005) “Economic Implications of an Ageing Australia”, Commonwealth of Australia, Canberra.

Turner, D., Giorno, C. DeSerres, A., Vourch, A. and Richardson, P. (1998), “The Macroeconomic Implications of Ageing in a Global Context”, OECD Economic Department Working Papers, 193. 